\title{
Building an airplane while flying it: One community's experience with community food transformation
}

\author{
Catherine Sands ${ }^{2} *$ \\ Partnership in Practice and University of Massachusetts, Amherst \\ Carol Stewart ${ }^{b}$ \\ Partnership in Practice and Mt. Holyoke College \\ Sarah Bankert ${ }^{c}$ \\ Collaborative for Educational Services \\ Alexandra Hillman ${ }^{\mathrm{d}}$ \\ University of Massachusetts, Amherst \\ Laura Fries ${ }^{\mathrm{e}}$ \\ Partnership in Practice
}

Submitted July 15, 2016 / Revised October 13, 2016 / Accepted October 14, 2016 / Published online

December 14, 2016

Citation: Sands, C., Stewart, C., Bankert, S., Hillman, A., \& Fries, L. (2016). Building an airplane while flying it:

One community's experience with community food transformation. Journal of Agriculture, Food Systems, and

Community Development, 7(1), 89-111. http://dx.doi.org/10.5304/jafscd.2016.071.012

Copyright (C) 2016 by New Leaf Associates, Inc.

\begin{abstract}
Across the country, local and regional food policy councils are collaborating to make healthy, affordable food more available to everyone. What ingredients are needed for a true collaboration that

${ }^{a}$ Catherine Sands, Co-Director of Partnership in Practice; and Lecturer at University of Massachusetts, Amherst, Stockbridge School of Agriculture.

b Carol Stewart, Co-Director of Partnership in Practice; and Ombudsperson, Mt. Holyoke College.

c Sarah Bankert, Program Manager, Collaborative for Educational Services.

d Alexandra Hillman, Masters Candidate in Public Health and Public Policy, University of Massachusetts, Amherst.

e Laura Fries, Consultant, Partnership in Practice.
\end{abstract}

changes social and racial equity dynamics? How can these collaborations influence systems, policy, and awareness in school food environments, specifically? This reflective case study describes some of the accomplishments and challenges faced by the multistakeholder Holyoke Food and Fitness

* Corresponding author: Catherine Sands, Stockbridge School of Agriculture, University of Massachusetts, Amherst; P.O. Box 61; Williamsburg, Massachusetts 01096 USA; chsands@pubpol.umass.edu

\section{Disclosures}

This evaluation was collaboratively conducted by Catherine Sands and Carol Stewart of Partnership and Practice with HFFPC partners and former staff, writers Sarah Bankert and Laura Fries, and graduate student Alexandra Hillman. It was supported by the W.K. Kellogg Foundation. 
Policy Council (HFFPC) for nearly a decade. Using a mixed-method participatory evaluation approach to lift up diverse partners' insights, we conducted key informant interviews with people who were engaged with the project during its eight operating years; focus groups and participatory asset mapping with stakeholders; and reviewed meeting notes from the eight years of the HFFPC. We identify several crucial ingredients that sustain equitable community-based collaboration: changing the dominant narrative, community and youth leadership and advocacy, and aligned multistakeholder partnerships. We also discuss critical structural and values-based challenges to multistakeholder organizing, including issues of trust, transparency, resources, leadership development, and differences in perceptions of racial equity in an underresourced, predominantly Latino community. As such, this case study investigates community engagement and effectiveness. It provides insights for those food policy councils and local coalitions endeavoring to build from within the community while accomplishing policy goals, and will help to further the practice of equity, community food policy and systems change, and governance.

\section{Keywords}

Food Policy Council; Coalition; Farm to School; School Food; Community Engagement; Food Justice; Youth Engagement; Community Based Participatory Evaluation

\section{Introduction and Literature Review}

A group of diverse dedicated people came together to improve the local food system of Holyoke, Massachusetts. This group became the Holyoke Food and Fitness Policy Council (HFFPC), and together they worked to upend traditional power structures in order to make policy changes that would improve access to healthy, affordable, culturally relevant, and locally grown food. Despite numerous challenges and a lack of long-term, visible systems and policy change, they made inroads and built on tangible accomplishments to influence attitudes and practices in the food and fitness environments. In this case study, we describe the successes and challenges of engaging community and youth together with nonprofit and agency partners in an urban initiative to make changes to the food system while providing opportunities for all to participate. We describe power-shifting among members and tactics for dealing with racial and economic disparities while sustaining the work with limited resources.

Many factors influence the health and wellbeing of an individual. The Kirwan Institute's report, "The Geography of Opportunity," (Reece, Gambhir, powell, ${ }^{1} \&$ Grant-Thomas, 2009) highlights a healthy and safe environment and political empowerment as two elements necessary for quality health. Meanwhile, racial segregation, mediocre schools, inadequate transportation, absence of affordable food markets, and high poverty rates contribute to a lack of opportunity in economic, social, geographical, and educational systems (Bell, Mora, Hagan, Rubin, \& Karpyn, 2013; Insight Center for Community Economic Development, 2013; Reece et al., 2009). Those living in neighborhoods that contain these negative elements struggle to access the opportunities (such as home ownership, good schools, adequate healthcare, clean and safe parks, affordable healthy markets, and decent jobs) afforded to the more privileged. Some solutions seek to "fix" the individual, but until the system is shifted to empower those in need, the opportunity dynamic does not change. It is not enough for public health professionals and partnering agencies from outside of these communities and neighborhoods to provide healthier choices: research suggests that when residents take an active role in improving neighborhood conditions, and in actually changing the systems and policies that preclude opportunities to build health and wellbeing, the result is a more positive impact on health and human potential (Ammons, 2014; Insight Center for Community Economic Development, 2013, Kang, 2015; Wolff, 2016).

Ammons (2014) discusses the need to construct new food-systems narratives that encompass the struggles and realities of people of color working to change the system and those who are directly impacted by its inequities. The old narrative

${ }^{1}$ This is the author's preferred capitalization. 
often omits the economic gaps that force families to make hard decisions about diet. In other words, shifting opportunity structures requires shifting assumptions: are the causes of diet-related illness simply due to poor diet? Or are they a result of the stresses of poverty, low minimum wage, lack of access to healthy affordable food and the time and resources to prepare it? (Ammons, 2014; Insight Center for Community Economic Development, 2013; Reece et al., 2009). While encouraging a healthy diet is an important step, the problem cannot be tackled until we examine its roots more deeply.

Fortunately, in the last two decades, food policy councils, local coalitions, and networks have assembled broad partnerships to incite foodsystems change. Community coalitions often form as a response to community problems. Community coalitions are designed with bottom-up organizing and decision-making, bringing together multiple organizations and stakeholders to align their actions through networking, cooperation, and collaboration (Foster-Fishman, Berkowitz, Lounsbury, Jacobson, \& Allen, 2001; Himmelman, 2001; Kadushin, Lindholm, Ryan, Brodsky, \& Saxe, 2005). Food policy councils are coalitions usually consisting of representatives and stakeholders from many parts of the food system, often including antihunger and food justice advocates, educators, farmers, food markets, nonprofit organizations, and citizens to address policy change with projects and advocacy (Burgan \& Winne, 2012; Harper, Shattuck, Holt-Giménez, Alkon, \& Lambrick, 2009; Scherb, Palmer, Frattaroli, \& Pollack, 2012). Some food policy councils form as coalitions, some by executive order, and others through legislation. Many at the local and regional level are independent nonprofits. The HFFPC was a community coalition convened by three nonprofit organizations, with a wide range of resident, agency, university, and city partners that embodied many of the characteristics of a local food policy council.

Over the past two decades, food policy councils have emerged as influential entities, often adopting a coalition model to bring communities together to target various aspects of the food system (the growing, harvesting, production, packag- ing, transporting, marketing, consuming, and disposing of food). Many food policy councils address community food insecurity, defined as a lack of adequate access to affordable healthy, fresh, culturally appropriate food (Burgan \& Winne, 2012; Coplen \& Cuneo, 2015; Harper et al., 2009). Most citizens do not play a role in shaping our food systems, despite the fact that the food policies in our communities and nation impact us on many levels, from environmental concerns to public health to justice and equity. Food policy councils can operate at the state, municipal, and local levels. Regardless of scope of operation, they generally provide a locus to discuss food-system issues, foster collaboration between sectors of the food system, evaluate and influence policy, and launch programs that address local needs (Harper et al., 2009). Most importantly, food policy councils also provide the potential for community engagement in all components of the organizing process and, therefore, can address inequities of opportunity and create longterm systems change.

Food policy councils often combine on-theground programs with policy targets as a comprehensive systems strategy to shift the way people obtain healthy, fresh, affordable food in their communities. While food policy councils are an effective way to make change, they can also be rife with conflict. When people who are marginalized with fewer opportunities define change-making as redistribution of opportunities or power, broader coalition consensus often erupts along the line of racial, cultural, ideological, and political opposition (Arnstein, 1969; Kadushin et al., 2005). This sort of division mirrors the very same systems the food policy council was designed to dismantle (Coplen \& Cuneo, 2015; Kadushin et al., 2005). There is a clear difference between going through the motions of community collaborative organizing and developing the power to actually shift the structures and systems that frame lack of opportunity (Arnstein, 1969; Reece et al., 2009). Because these systems have historically marginalized and excluded community residents, community organizing without redistribution of power is a frustrating and all-too-familiar experience for community members. To achieve equity in community food 
change organizing, people of color, youth, and other traditionally disenfranchised groups must participate in governance and decision-making as the leaders, initiators, advocates, directors, and steering committee members (Bell \& Lee, 2011; Lee \& Navarro, 2016).

With their Collective Impact model, Kania and Kramer describe five essential factors that contribute to coalition success: establishing a common agenda, participating in mutually reinforcing activities, communicating continuously, having support from a strong backbone organization, and securing long-term funders (Hanleybrown, Kania, \& Kramer, 2011, 2012). This design has helped frame over a decade of effective community-wide coalition work, and served to shape the evolution of the HFFPC. However, it falls short of describing the inherent messiness of actual on-the-ground community change partnerships and authentic and equitable community engagement, while also missing the social justice change work that community-based organizations do to address root causes of their community issues (Wolff, 2016).

In order to avoid replicating power structures that disempower groups already struggling with diminished opportunities, those involved in coalition building must intentionally and carefully consider how to address leadership and racial and economic equity within their coalitions (Ammons, 2014; Giancatarino, \& Noor, 2014; Kadushin et al., 2005). It is only with clearly articulated and continuously embedded understanding of structural racism and the resulting lack of opportunities for specific racialized groups that collaborative organizing can be successful. When community members are truly a part of all aspects of decision- and change-making within the food system, coalitions and food policy councils can work together across race and class to make positive changes (Ammons, 2014; Arnstein, 1969; Giancatarino \& Noor, 2014; Kadushin et al., 2005; Kang, 2015; Lee \& Navarro, 2016).

In addition to clearing the enormous hurdle of creating equitable participation within a food policy council, the literature points to a number of other challenges as well. For example, when municipal entities (schools, health departments, and universi- ties) and large influential agencies join with smaller, less powerful entities (nonprofit agencies, neighborhood organizations, and community residents), many different agendas are at the table. These varying agendas can be heightened by the different gradients of power and influence that each entity has in the city (Coplen \& Cuneo, 2014; Harper et al., 2009; Wolff, 2016). Moving towards a core purpose while reaching the needs of the many groups involved (and not just the most powerful groups) takes careful organizing, communication, and collaboration. Perhaps also unsurprisingly, the literature points to common hurdles of budgets, resources, time, and strong personalities who dominate consensus or agreement processes (Coplen \& Cuneo, 2014; Harper et al., 2009).

These challenges notwithstanding, we have observed through the example of our Food and Fitness peer coalitions throughout the country that when coalitions establish equitable governance structures and collaborative processes, they begin to "change the narrative" of traditional power structures by providing ladders for community residents to voice, take action upon, and participate in change making and policy processes. From our experience, coalitions and food policy councils that collaborate across race and class generate the possibility for broad systems change. When successful, they are able to align across stakeholder sectors (community, agency, municipality) and systems (food production, distribution, institutions, hunger) and can address the underlying causes of health disparities.

The Holyoke Food and Fitness Policy Council (HFFPC) strove to improve the local food system by achieving and developing diverse stakeholders; working from the ground up and developing leadership; aligning partners; building trust by not replicating traditional opportunity structures; and organizing to change systems and policies. This case study delineates successful strategies and acknowledges some pitfalls to broad-based multistakeholder organizing for food change. We contribute to the literature by directly addressing the power imbalances and inequities witnessed in the process. We illuminate how to seek power sharing amongst communities and agencies, and the importance of involving young people in this process, 
while accomplishing policy goals. And, by design as a participatory evaluation, this case study affirms a collaborative process, thereby shifting the typical top down opportunity dynamics seen in cities like Holyoke. The examples we use are from HFFPC's farm-to-school work, one component of its overall community food initiative, because they represent some of the clearest successes and struggles of the collaborative.

\section{The Holyoke Food and Fitness Policy Council}

Holyoke is a small city located in the Massachusetts Pioneer Valley that was built on paper mills, drawing immigrant workers in succession from Germany, Ireland, Canada, and Poland. As these immigrants prospered enough to move up the hill and out of downtown tenement housing, they established a strong and vibrant middle class, running the schools, city government, and businesses. In the 1960s and 1970s, Puerto Ricans began traveling to Holyoke to work the mills but soon after, the paper industry began to relocate to the Global South, and jobs in Holyoke waned. A distinct ethnic and income divide emerged between neighborhoods, with the middle-class neighborhoods up the hill and the poor neighborhoods downhill (the "Flats") facing food insecurity, health disparities, crime, high drop-out rates, drugs, and violence (Gottlieb \& Joshi, 2010; Graham \& Cornwell, 2009). Holyoke is currently the poorest city in the Commonwealth, with $29.6 \%$ poverty (U.S. Census Bureau, 2016). Its schools, which serve approximately 6,000 students, face the double challenge of providing nourishment to many food-insecure children and increasing academic achievement (Massachusetts Department of Elementary and Secondary Education, 2015).

In 2007, Nuestras Raíces, an urban agriculture and community development organization, together with the Holyoke Health Center and the Greater Holyoke YMCA, received a multiyear Food and Fitness grant from the W. K. Kellogg Foundation to improve the health of vulnerable children and families. The group wanted to increase access to healthy food and safe places to exercise through The Holyoke Food and Fitness Policy Council
(HFFPC). They joined eight other communities around the nation in this endeavor. The nine communities supported each other in developing local strategies through intensive local organizing, sharing these at grantee convenings, and taking advantage of technical assistance provided by the foundation.

The new Holyoke Food and Fitness Policy Council became the backbone of strategic efforts to shift Holyoke's food environment and health outcomes. Three working groups-youth residents, community residents, and agency members-were represented in equal number on the governing steering committee. Together they led a planning process that resulted in a community action plan (CAP) targeting improvements in community food access, school food, youth opportunities, and the built environment and active living.

The HFFPC had significant initial results from its organizing for school wellness, community food, and healthy living, not the least of which was creating new ways to bring together people from many backgrounds and perspectives to collaboratively create change. Holyoke is located in the Pioneer Valley, which has some of the most fertile soils in the state, and is home to several vibrant community engagement efforts. The nationally recognized Nuestras Raíces, a nonprofit economic and agricultural development organization, has over 180 families gardening throughout the city, a 30-acre (12-hectare) urban incubator farm, and a youth leadership program. Holyoke's resilience is reflected in the abandoned lots now being repurposed by grandparents and young children to grow vegetables together. The Greater Holyoke YMCA sponsored a small group of youth activists who initiated a teen rebuild-and-earn-abike program (Holyoke Urban Bike Shop). The youth convinced the city to paint bike lanes and install bike racks in the Holyoke streets, and later became members of a city-sanctioned biking and walking committee, which introduced the city's first Complete Streets legislation. ${ }^{2}$ The Holyoke

\footnotetext{
2 "Complete Streets" refers to policies requiring streets to accommodate all users (to include marked lanes for biking and walking, and safe sidewalks and road crossings).
} 
Health Center developed citywide wellness initiatives in schools and health centers.

This mix of organizations and community that made up the very heart of the HFFPC is illustrated with its organizing around school food. Farm-toschool programming "enriches the connection communities have with fresh, healthy food and local food producers by changing food purchasing and education practices at schools" (National Farm to School Network, 2016, para. 1). Farm-to-school organizing can empower young people and their families to create their own food environment-to grow their food, cook it, gain skills, and affect public policy (Weaver-Hightower, 2011). In Holyoke, a city with limited opportunities, the HFFPC brought the needed resources, strategy, funding, and structure to align and empower many stakeholders in the school community to organize for more delicious and healthy meals. Before the HFFPC organizing efforts, the schools lacked the resources, partnerships, and administrative will to shift school food procurement and preparation practices. Due to challenges in resources and student performance, the district prioritized achievement above all else, and this meant that improving the school food environment was a lesser priority. Holyoke Public Schools (HPS) contracts with large foodservice purveyors to serve meals. Two separate contracts with vendors sequentially spanned the time frame of this article. The fact that farm-toschool was a new concept for each purveyor created an opportunity for the HFFPC to support them in improving school meals and navigating purchasing from local farms when possible. The diverse HFFPC coalition partners designated improving school food as one of several strategies to address the food insecurity, overall health, and critical thinking skills among Holyoke's most vulnerable children. With its resources and ability to bring together foodservice staff, school administrators, parents, youth, and nonprofit leaders, HFFPC became the backbone for a farm-to-school strategy, implementation, and evaluation in Holyoke for nearly eight years.

\section{Methods}

This evaluation followed the collaborative approach of the HFFPC: we adopted participatory methods, in which the multiple stakeholders created and analyzed knowledge together (Coombe, 2005; Kang, 2015; Zukoski \& Luluquisen, 2002). In participatory evaluation, stakeholders (partners, funders, key decision-makers, community residents) actively engage in developing the evaluation and the phases of its implementation (Zukoski \& Luluquisen, 2002). In this case study, we followed the participatory evaluation structure in order to provide an opportunity for key stakeholders to analyze successes and challenges together, feel empowered by the work they had done, and use these findings to create action and change.

In 2009, Partnership in Practice (which consists of Sands and Stewart, the two lead authors of this paper) contracted with the HFFPC to conduct the annual Cross Site Evaluation developed by the W. K. Kellogg Foundation. With the HFFPC, Partnership in Practice tracked systems and policy change outcomes resulting from the HFFPC's community action plan efforts to improve community food, school wellness, youth development, and active living. We adopted a participatory evaluation approach both because the HFFPC valued and the foundation called for processes generated collaboratively with the community. Our evaluation of the HFFPC includes six years of field engagement to understand the processes involved in implementing the initiative. We regularly attended and took field notes of steering committee meetings, issue-based subcommittee meetings, whole community listening sessions, and community events. We also conducted interviews with staff and key partners throughout the life of the grant (2009 to 2015). During those six years, we developed participatory methods with community members, youth leaders, and agency partners to track outcomes, and collaborated with researchers at the University of Massachusetts Amherst on a PhotoVoice and a plate waste evaluation. We view evaluation as a way to identify shared values, understand systems change and the root causes of community challenges, build advocacy and planning skills, and foster strong partnerships. Participatory methods can include identifying relevant questions, designing appropriate evaluation methods, gathering and analyzing data, reaching consensus about findings, and creating a plan of action (Zukoski \& Luluquisen, 
2002). Previous evaluations that are relevant to this evaluation include a 1,000-person food access survey, a school plate waste evaluation, a youth PhotoVoice assessment of the school food environment, a mixed-methods evaluation of the Kindergarten Initiative, and youth-driven evaluations of the Call for Partnerships mini-grant program.

The W. K. Kellogg Foundation invited and funded us to construct and write this case study evaluation. We adopted a mixed methods participatory approach with four segments:

1. Review of HFFPC Documents: We began by reviewing results from the previously mentioned cross-site evaluations from 2007 to 2014 , notes from steering committee and subcommittee meetings, and early interviews. We used NVivo qualitative coding software to code many of the key documents. We discussed recurring themes and identified misunderstandings or conflicts that arose during the previous years of meeting, community work, and funding. We came up with theme categories: School Food, Youth, Leadership, Power, Listening, Voice, and At The Table (Governance). While the HFFPC had many examples of successful strategies to improve community food, wellness, and the built environment, we decided to highlight the school food organizing examples in this case study, as the school food work illustrates community successes and challenges within the broader institutional and political landscape of Holyoke.

2. Key Informant Interviews: We conducted 22 key informant interviews between July and September 2015 with former staff, community and youth leaders, and agency partners who represent the broad demographics of what had been the HFFPC Community Leadership Committee, Youth Leaders, and Agency Alliance. We recruited interviewees who were present during the various stages and lifetime of the HFFPC, including planning, implementation, dissolution, and emergence as a new program. Interviewees were offered gift cards. To maintain confidentiality, we refrain from using names, but we identify council affiliation to provide context. Key to the participatory evaluation process, the interviews offered the partners an opportunity to reflect on successes and challenges of their project. We recorded and transcribed these interviews and coded them with NVivo software (see Appendix for interview questions).

3. Community Dialogue: We identified three themes concerning emergent challenges from the interviews. The themes are leadership development and mentoring, trust and transparency, and project resources. We brought forward these themes for reflection and discussion among the group of HFFPC partners, youth and community leaders, and former staff at a Community Dialogue. We invited 40 people who had been involved with the HFFPC as staff, youth or community leaders, and agency partners to this evening of focus groups and interactive activities. We used a combination of email, text, and phone calls to reach out to partners, and tried several times to reach people we had not heard from. In attendance were 19 people (eight had also been interviewed), including former youth, community members, former staff, agency partners, and three evaluator-facilitators. We chose the format of face-to-face engagement with a meal catered by a nearby Puerto Rican restaurant, because in-person gatherings are personable, authentic, build relationships, and are the preferred means of communication and dialogue in the Holyoke Latino community. Process, in this instance, is as equally important as outcomes (Kang, 2015; Zukoski \& Luluquisen, 2002). Over the years the HFFPC learned that meeting over a healthy, culturally relevant meal, offering childcare, and holding meetings at convenient times for community parents and youth 
leaders (evenings) make these meetings more possible and attractive for a vibrant mix of people to attend. The total number of participants in interviews and community dialogue was 30 , including four youth leaders, five community leaders, and 21 agency members, seven of whom are Latino community leaders working for communitybased organizations. Therefore, half of the representatives were community members.

4. Asset Mapping: We then asked those in attendance to identify and write HFFPC's school food organizing milestones on a timeline posted on the wall (see Figure 1). The timeline, or asset map, provided partners with the experience of compiling and seeing the range over time of the collaborative's farm-to-school accomplishments, and of appreciating the varied and long-term nature of success. Thus, together partners clarified the community organizing and partnership alignment strategy successes. As we reviewed focus group and interview notes, a theme of difference in language and perceptions of equity also emerged, which we discuss alongside the other three. Finally, we circulated the manuscript to all interviewed, and received comments (incorporated in the final text) from four partners.

\section{Limitations and Potential Conflict of Interest}

This reflective case study has some limitations as a participatory evaluation. Due to time and resource constraints, we could call this more of a "collaborative approach," in which the evaluators led a process with considerable partner input, rather than a participatory approach, in which the participants and evaluators would be jointly involved in all stages of the process, including data collection, analysis, and writing (Zukoski \& Luluquisen, 2002). Partners representing all stakeholders were involved in identifying potential interviewees, were interviewed, and contributed to analyzing findings in the community dialogue. However, we analyzed the data further, wrote drafts, and then invited the partners to review and make comments on the manuscript.
Authors Sands and Stewart, under the name Partnership in Practice, have worked collaboratively as third-party evaluators with HFFPC since 2009; author Bankert has been part of Partnership in Practice since 2011, and author Fries since 2013. They work for Mt. Holyoke College (Stewart), University of Massachusetts Amherst (Sands and Fries; Hillman is a graduate student there), and as a freelance community food project evaluator (Sands). Some of these food projects are also HFFPC partners. The HFFPC members had differing points of view about governance, resource allocation, and community engagement. To avoid possible bias, we invited HFFPC stakeholders of multiple perspectives to be interviewed and to attend the community dialogue focus groups. We also invited an outside facilitator, funded by the W. K. Kellogg Foundation, to lead these sessions in the early participatory analysis process. Our data collection was for the purposes of evaluation. The New England Independent Review Board certified our research protocol. All authors have participated in human subjects trainings; we informed participants of their rights, obtained their signed consent to participate, and have protected their confidentiality.

\section{Results and Discussion: Emergent Themes from Interviews and Dialogue}

The interviews, community-generated school food asset mapping, and community dialogue focus groups (as well as HFFPC documents) revealed successful strategies that the community members, youth leaders, and aligned partners employed to begin to change the school food system. A partner notes:

The school food work had a huge amount of integrity because it worked on many levels at once. Getting the young people involved, changing the food culture, continuously trying to engage the food service and not shrinking back from that, even when the foodservice providers changed, knowing that they had to be a critical partner. (Partner, Interview, 2015) 


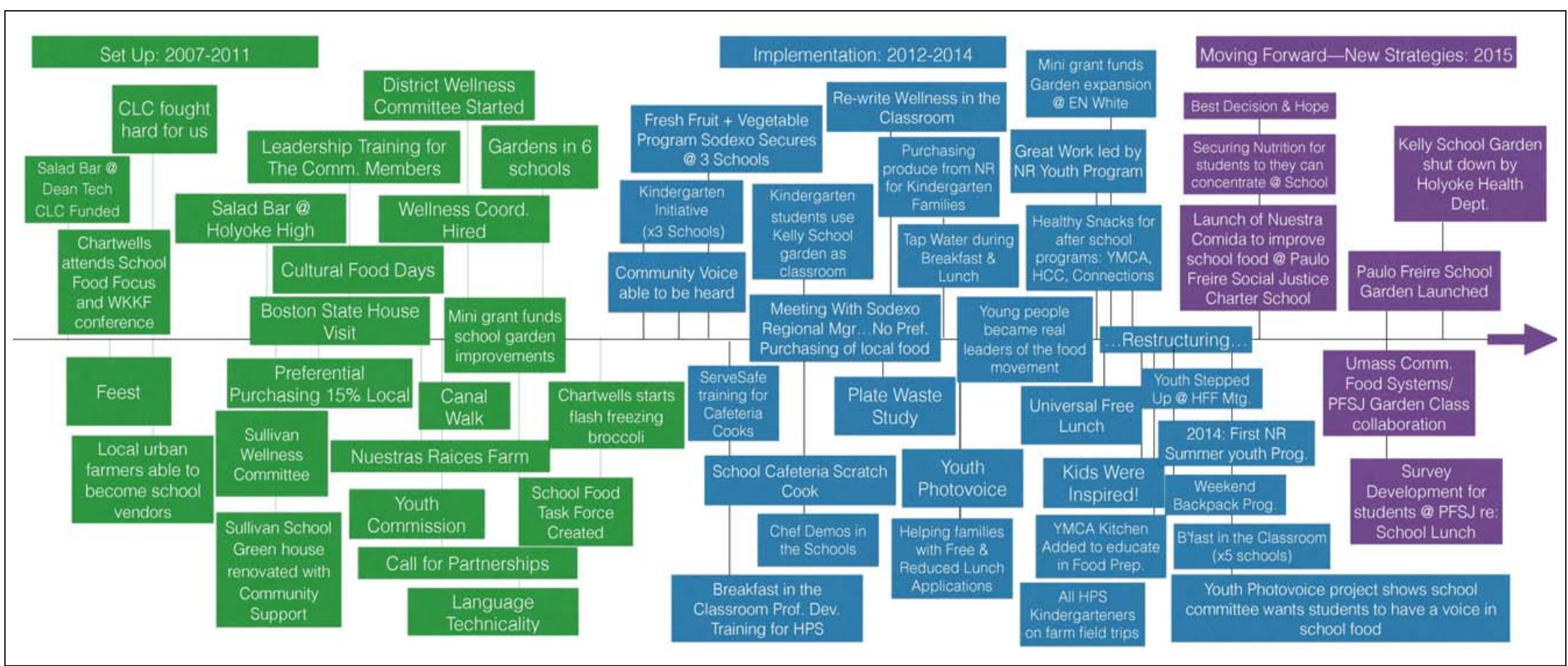

Those interviewed also discussed the challenges they experienced as part of a coalition working on multiple aspects of the health and fitness environment, such as barriers experienced regarding leadership development and mentoring, trust and transparency over project resources, and perceptions of equity. Below we highlight three stories that demonstrate successes in bottom-up community engagement, and then discuss three primary challenges to sustaining the HFFPC.

\section{Examples of Early Successful Strategies Led by Holyoke Community Members and Youth}

Community Members Change the School Food Environment and teachers struggle to improve student achievement, top-down decision-making is the norm. The HFFPC attempted to turn this upside down by organizing a broad coalition. The aim was to shift the "narrative" about young people's perceived disinvestment in the school food environment to demonstrate that the community (parents) and students like to eat healthy food. What followed changed the power structures associated with decision-making about school food.

In the first years of HFFPC, the Community Leaders Council (composed of community residents who were also school parents) chose to designate W.K. Kellogg Foundation grant funds to launch a prototype salad bar, stocked with healthy options and fresh produce from Nuestras Raíces urban farm, through a partnership with Dean 
Technical High School's Culinary Arts Program. This was the first time that Puerto Rican students (over two thirds of school students) were eating vegetables grown by Puerto Rican urban farmers in their school lunch program.

By installing the school system's first salad bar (Figure 2), parents, youth leaders, and agency partners set out to "change the predominant narrative" about low-income students of color and their families (Ammons, 2014). The existing school food narrative, argued by the school food service and generalized more broadly in our culture, could be summed up as children and teens do not like to eat fresh fruits and vegetables, prefer processed foods such as chicken nuggets, and that fresh produce is expensive (HFFPC, 2009). This narrative that children do not like fresh food often omits the economic gaps that force families to make hard choices about meals because fresh vegetables are either too expensive or are not readily available (Ammons, 2014). Indicating the narrative change resulting from the salad bar, a former student notes: "I'm on the football team and I eat from the salad bar to drop weight and it's healthier. Our coach recommends it to us" (HFFPC, 2009). The broad-reaching resulting scope of this change included improved school meals, new income to the Nuestras Raíces farmers, and new connections between a food service director and executive chef and the broader national farm-to-school organizing community. Equally important, community residents of color changed the predominant HPS narrative that parents of color were not typically involved with school food change by both designing and funding a salad bar with produce sourced from an urban farm. As one resident noted, community residents " ... [had] access to [grant] money to do what they believe is good for them" (Interview, 2015). This marked a dramatic shift: while a nurse had organized a small wellness committee in one school to address critical hunger and diet issues, parent participation was not widespread and not representative of the Latino population (HFFPC, 2009).

Parents and students demonstrated their enthusiasm for healthy meals and fresh salads and their eagerness to be part of structural change by designating funding, participating in the salad bar tracking committee, and therefore identifying best practices. Holyoke High School subsequently renovated its salad bars as well. A former youth leader describes the impact on participation:

It took a while to see but [it] made a huge change. The younger people at Holyoke High go to the salad bar now. More and more people go to the salad bar [rather] than eat pizza and hamburgers. They built it and remodeled just when we were in school. Not a lot of people grabbed it at first. I started grabbing it and many people saw and then everyone wanted it. (Former youth leader, Interview, 2015)

The students at the school initiated a committee to track the pilot salad bar participation with the executive chef, evaluator, and farm manager,
Figure 2. Salad Bar

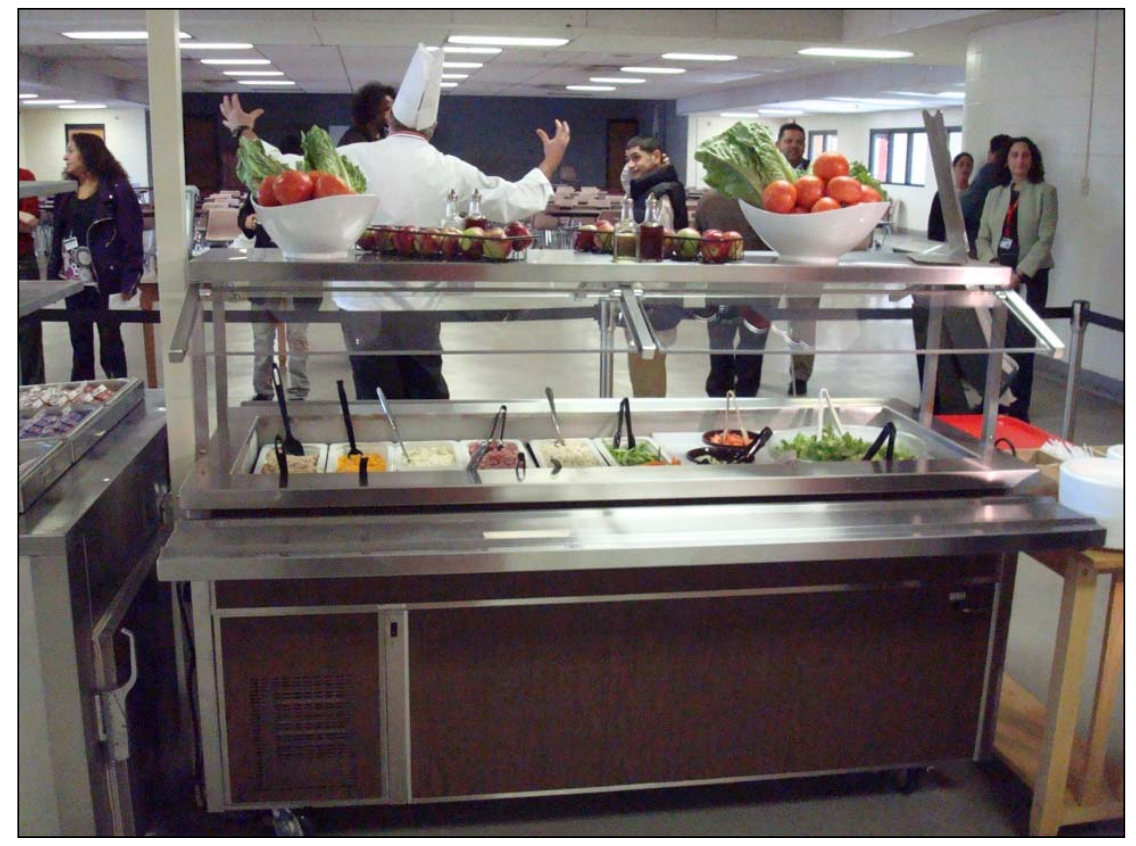


laying the foundation for the first multistakeholder School Food Task Force.

Following the salad bar pilot, The HFFPC created leadership and advocacy opportunities, training, outreach, awareness-building, and a funding structure for community-identified food projects. As a leadership example, a parent joined the search committee for a food vendor and advocated for a provision requiring preferential purchasing of $15 \%$ local produce. Kindergarten Initiative family cooking demonstrations engaged parents in healthy food curriculum. Parents joined the selection committee for A Call for Partnerships, a small grant program that provided funding and technical assistance to community-identified and -led projects that included a school garden expansion, a school wellness curriculum, a walking school bus, and the first foodservice provider weekend backpack program to combat family hunger (Sands, Bankert, Rataj, Maitin, \& Sostre, 2014). And finally, youth and adult community members (as well as staff) remarked on the value of feeling part of a broader movement, a sense that they gained from attending and presenting at local, regional, and national food security and farm-to-school conferences.

\section{Youth as School Food Policy Change-Makers}

All those interviewed for this reflective case study

\section{Figure 3. Image from the PhotoVoice Project}

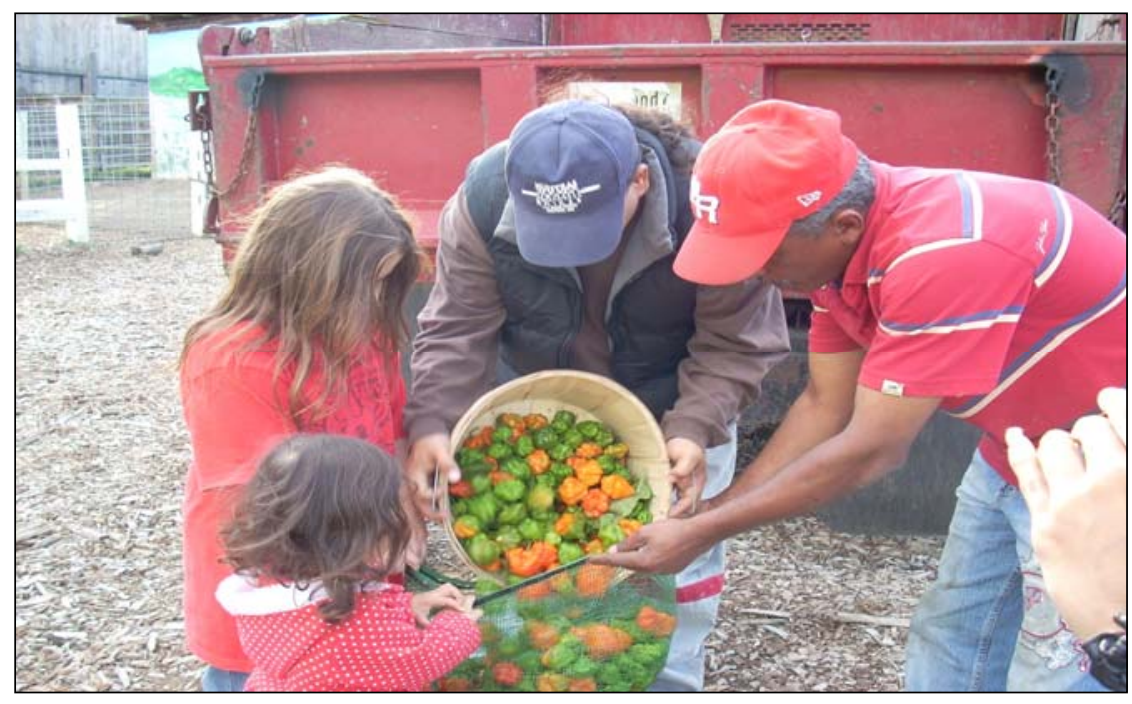

identified youth empowerment as a major success of the farm-to-school organizing. The PhotoVoice collaboration with the University of Massachusetts Amherst illustrates how youth came to see themselves as part of the school food solution (see Figure 3). In 2012, a group of Nuestras Raíces youth leaders picked up cameras and took pictures of a moment in time when the school food vendor had agreed to purchase lettuce, peppers, and tomatoes from the Nuestras Raíces urban farm. They interviewed the farmers and the executive chef to learn how the vegetables were grown, packaged, transported, and served in the schools. When the food vendor's contract came up for renewal, the students presented their findings to the school committee (board), saying, "We care about healthy food. When kids have a chance to eat healthy food we start liking it. Students want a say in the decisions made about what we eat in school" (HFFPC, 2012; Interview, 2015). They later invited city policy-makers, parents, and the broader community to an exhibit of their PhotoVoice project, and took it to national food and youth conferences. A former partner described the significance:

The youth presented to the School Committee. It's not like there's great food in the schools yet, but the idea of seeds planted was huge for those kids. We don't know when and where these will bear fruit. But the idea of activism in the youth, that they can speak out. Some piece of this has yet to be seen. (Partner, Interview, 2015)

At the same time, the youth leaders studied food sovereignty and food justice, marched with the Coalition for Immokalee Workers, and studied the history of Puerto Rico. These opportunities helped the youth become recognized leaders in their community and nationally, to 
see themselves as agents of change and part of a larger movement to change food systems and racial justice. A parent and community partner notes:

One of the great nuggets was the youth learning about their Puerto Rican history and connection to land. When I think of my daughter feeling her empowerment, learning her connections to Puerto Rican history. Watching her blossom from that. When [the youth director]...could do that and in that position to be a mentor. Training students to be advocates in the school was critical. Talking to the school department. Training them to have the conversation in front of the school committee. These are things that youth in Holyoke don't know how to navigate. In Puerto Rico, there are no school committees. When people come here, it's a new concept. (Community partner and agency leader, Interview, 2015)

The youth were able to step up and take advantage of what John Kingdon calls a "policy window," an opportunity to advocate to the school committee the need for a foodservice provider that would work collaboratively and creatively within a broken national school lunch program (Kingdon, 2010). A school parent noted: "Kids or parents get blamed for unhealthy eating, but schools are contributing to the fact too. The PhotoVoice project showed them [the city and schools] the value of what healthy food could do for kids" (Community resident, Interview, 2015). When youth are seen as the catalysts of change, as the experts, their world view and confidence has the potential to shift. This new self-confidence and sense of belonging can be a determinant in the trajectory of life opportunities (Insight Center for Community Economic Development, 2013; London, 2007; Weaver-Hightower, 2011). A partner noted "With the PhotoVoice project an amazing space was created. We actually created a new kind of structure in the community. john powell talks about opportunity structures. This is first time I have seen it play out" (Interview, 2015). One youth leader noted a new sense of his role in a broader movement:
I had a sense of different schools changing, like we were impacting change. Not just here, all over the place, all over the country. They saw us doing it. When we went to [the W. K. Kellogg Foundation Food Community conference in] Detroit, people said that they admired what we were doing, wanted to try using similar examples to what we were doing. (Interview, 2015)

\section{Aligning Multistakebolder Relationships}

In order to create broad traction within the school food system, the HFFPC gathered the different stakeholders in the school food environment to collaboratively design a change process specific to the school food environment. For the first time, students were given an opportunity to go beyond the common complaint of "the food is nasty" by joining with school administrators through the newly formed School Food Task Force, one of two working groups of the HFFPC. The School Food Task Force followed the coalition model and included foodservice staff, students, parents, and nonprofit partners to voice challenges and strategize- across potential different points of viewabout school food-systems change. By meeting regularly to explain school lunch program regulations, share strategies and plan menus, the relationships formed between the executive chef, HFFPC partners, and youth led to a more responsive environment for collaboration. These collaborations resulted in groundbreaking moments, including the purchase of local produce for the salad bar, a regional effort to flash freeze broccoli, youth-led cultural meals, cooking classes for cafeteria workers, and a Kindergarten Initiative with taste tests and farm field trips (HFFPC, 2009-2014). The relationships were tracked over time in the Cross Site Reports and through in-depth interviews with food service staff partners.

To support the early work of the School Food Task Force, and to incorporate health more broadly into the school environment, the HFFPC partners designated funds to hire a wellness coordinator (a chef formerly on the staff of the Culinary Arts program), to build a broad wellness strategy from within the school district. She cultivated strategic partnerships within and outside the district 
and leveraged those partnerships for further grants and resources (Interview, 2015). "One of the reasons school food change happened was because she [the school wellness coordinator] never stopped walking down the hall and talking to people" (Staff member, Interview, 2015). She understood the value of building relationships with all groups that had a stake in the school food environment, and helped each group recognize its shared interests in improving that food. Evaluation data shows a 46\% increase in HFFPC ongoing partners and a $30 \%$ increase in strategic partners between 2008 and 2011 (Figure 4) (HFFPC, 2012). This strategy of building relationships and a culture of wellness through the work of the wellness coordinator and the School Food Task Force created significant inroads with the administration, food service providers, teachers, students, and families.

As a former staff person noted, "this was the first time the Holyoke Public Schools opened up to work with partners, write grants with them, allow them to visit the schools, [and] collaborate with food service and the teachers" (Staff member, In- terview, 2015). HFFPC became the "go-to" entity for school food change. She continues:

One of our greatest accomplishments with school food was that we created a movement. We moved people to talk about issues they had never talked about before: equity, justice, racism, wellness, school food. We were the ears for the community needs. We were the channel that people looked to partner with to look for grants. (Staff member, Interview, 2015)

Spurred on by the efforts of the HFFPC, the schools have undergone several structural changes to prevent food insecurity. A broad institutional effort to improve participation in school meals has taken the form of universal free breakfast and lunch, breakfast in the classroom in some test schools, fresh fruit and vegetable snacks, a weekend backpack program for food-insecure children, some scratch cooking in school meals, and cultural food celebrations. While not directly spearheaded

\section{Figure 4. Number and Type of HFFPC Partners, 2008 to 2011}

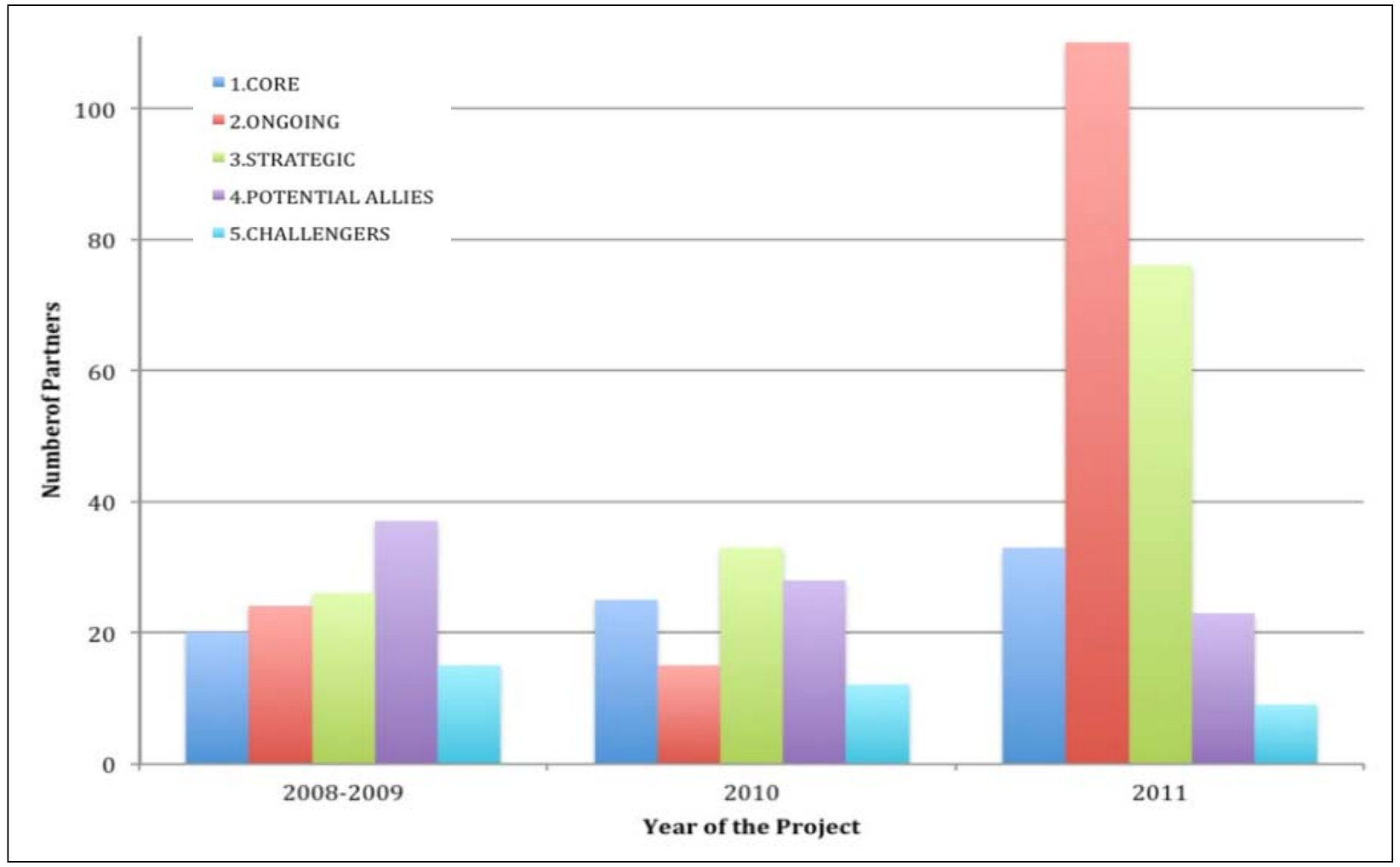


by HFFPC, the groundwork was laid for these significant shifts in school food policy and practice by the efforts of the school wellness coordinator and the School Food Taskforce. By building relationships, aligning partners, knocking on doors, writing grant proposals, and making visible the community priority of ensuring healthy and delicious meals for all children in the schools, HFFPC contributed to these outcomes. Less progress was made in consistently procuring and serving fresh, locally grown produce, or in embedding healthy food programs into the curriculum.

\section{Challenges in Sustaining Successes}

The school food efforts bubbled up, took hold, and then dissolved, perhaps due to the dire financial and achievement challenges of the school district, the relative immobility of a new food service contractor's corporate policies, and a stalled HFFPC that was experiencing staffing and structural changes that narrowed its reach and efficacy. Community engagement waned, and the core HFFPC partners became divided about leadership and governance. As the backbone HFFPC support came apart, farm-to-school programs did not have the consistent attention, resources, and leadership needed to sustain them in a struggling district. As a result, the broader integration of local produce in school meals with institutional support for building critical thinking curriculum about food has not been sustained. At a coalition level, the collaborative experienced inertia due to this lack of a sustainable model for permanent change. Below we categorize the stakeholders' observations of why these coalition breakdowns occurred.

\section{Community Resident Engagement in Policy Change and Leadership Development}

The HFFPC wrestled with designing and sustaining a structure that would effectively engage school parents and community members as a whole. A partner noted, "building the airplane while you are trying to fly it is a tough dynamic" (Interview, 2015). The HFFPC had planned to build a cadre of parent organizers through school wellness committees, but these never fully materialized. Perhaps this correlates to the HFFPC's larger struggle to build and sustain the community leaders' capacity and presence over time. A former director notes, "We fell short of getting new faces to the table. There was a lack of new recruitment from the community" (Interview, 2015). The HFFPC partners failed to reach a central goal (stated in the Community Action Plan) of supporting community leaders to attain permanent positions of leadership — to be on boards and committees and, ultimately, to have relevant and respected leadership roles that could grow into paid positions within the project.

The early steering committee was structured so that community residents would be part of all decision-making for the HFFPC. A resident noted, "I thought the [early] steering committee was a great opportunity to mentor people, to give voice to youth. Not one sole organization to dictate what the grant should or shouldn't be doing. [Community residents had] access to [grant] money to do what they believe is good for them" (Community resident, Interview, 2015). During the implementation phase, the HFFPC redesigned its governing structure and never adequately cultivated a new strategy and structure through which community residents could participate in decision-making within HFFPC. While many strategies were discussed about how HFFPC could achieve the central goal of the action plan to support community leaders to attain permanent positions of leadership, no structured and sustainable strategy was implemented to achieve this goal.

Additionally, a long-mentioned concern from residents involved in the HFFPC about the need for the project to support job creation both within HFFPC as well as in the greater community never became a concrete goal within the Community Action Plan. The emphasis that Latino community residents placed on the importance of creating new job opportunities illustrates the extent to which poverty and economic oppression functioned within their lives. The need for skills and training was a motivating factor for some residents to become involved in HFFPC, but many expressed disappointment and confusion as to why "outsiders" were most often hired for coalition jobs. Those Latino residents that were hired for coalition jobs-two out of a total of nine-at times struggled to manage the hefty workload, competing demands of organizational partners and community 
groups, complex project management duties, and training on content knowledge regarding effective policies and practices. Many staff members coming into the project lacked adequate scaffolding to support their orientation and growth into their role, and Latino community residents coming in without commensurate formal education and experience in leading coalitions were especially in need of strong mentorship and support through their host organizations (Interview, 2015).

This challenge in galvanizing community engagement, as well as the lack of focus on creating and supporting Latino residents in nonprofit careers, reflects ideological differences between the core partners. Many agencies in Holyoke, including the majority of HFFPC's lead partners, follow a predominantly "service" model of providing critical health, education, and housing services to its low-income community of color. Additionally, traditional structures of power remained with regard to race, as whites tended to staff executive positions in more powerful service-based organizations, while Latinos led the more grassroots organizations (Kadushin et al., 2005). The service approach adopted by some of the major institutions clashed with community organizations' empowerment model, which has been described by Wallerstein as "a social action process that promotes participation of people, organizations, and communities toward the goal of increased individual and community control, political efficacy, improved quality of community life, and social justice" (Wallerstein, 1992, p. 198). One partner described dissatisfaction with the larger service agencies approach of,

...giving handouts versus a hand up. People say Holyoke is apathetic. Once jobs left Holyoke the nonprofit industry became the new economy and the new industry. It's worse off than when I first came. All the organizations fight for the same money. It's a turf issue. They see the community as a deficit, not an asset. I don't think the community is apathetic. It has no voice. It's a system that sustains but does not empower. (Interview, 2015)
The different approaches employed by these partners resulted in stalled community involvement. One staff member noted, "the community piece-to think through how to put together the pieces around genuine and authentic communication, building in structures, sustaining that engagement and impacting data, policy. I don't think we did it well. We really struggled" (Interview, 2015). Core partners became divided between those serving and those representing the community.

\section{Trust and Transparency and Differing Impressions of Project Resources}

Many of those interviewed for this paper noted that lack of trust and transparency between partners became a growing challenge to program implementation.

No one really knew how to do this work. There was a vision, but collaboration was a word. It takes a lot of practice to do it, especially in Holyoke, where there is a lot of competition for funding and resources. (Staff member, Interview, 2015)

While differing points of view were initially viewed as a strength in the HFFPC, as disagreements emerged between convening organizations around financial management and how to disburse funds, the decision-making processes began to resemble more traditional business practice and less a community-centered model. This lead to a tension between community members and agency members; it appeared that the differing points of view between stakeholders of this community-based change process were not an asset in this case, but impassable. The apparent replication of a topdown decision-making model was one that community members recognized and distrusted.

Conflict arose over which organization would serve as fiscal agent, how to prioritize spending the money, how to allocate it between organizations, and whether and how to pay community members for their participation (through stipends, hourly, or part-time jobs). A former staff member notes, "If we're really going to change-if food work has the ability to change things, we have to create jobs, not 
just give stipends. We were stuck arguing over stipends" (Staff member, Interview, 2015). Another posited, "In Holyoke, people just need money" (Partner, Interview, 2015). The discord about which organization held the grant funds and about how to build a community leadership ladder with appropriate remuneration resulted in distrust between the partnering organizations and the community.

As the steering committee underwent restructuring, it reached out to other Latino-led, community-based organizations to be part of the governance structure. The process of rebuilding collaborative governance was long and burdensome to small, underfunded organizations, and several chose to step back, leaving the original core partners. The director of a smaller, grassroots, original partnering organization - the only Latina steering committee participant who was also a community member-became disenchanted with the decisionmaking process and ceased attending steering committee meetings. This resulted in a lack of community representation and racial and cultural diversity on the steering committee (Interview, 2015). Sustaining multiple points of view and representation on food policy councils seems to be a common challenge (Coplen \& Cuneo, 2015; Kadushin et al., 2005; Packer, 2014). One partner notes, "I don't think anybody from the organizational side wanted to seem like they had the power but that's how the community saw it. How would we have set that up differently?" (Interview, 2015). This illustrates different perceptions about power: while some agency representatives thought they were sharing power, the community and some grassroots organizational partners did not see it that way.

Some interviewed participants noted that these different perceptions manifested in the unequal distribution of funds between core partnering organizations. Small, underfunded organizations, larger organizations, and community members needing work all struggled together to allocate funds. "When you give a group of organizations in a struggling city the promise of a lot of money and tell them to work it out together it's a recipe for disaster" (Partner, Interview, 2015). Conflict arose over how to prioritize spending the money, how to allocate it between organizations, and whether to pay community members for their participation.

\section{Differences in Language and Perceptions of Racial Equity}

Lack of trust and differing perceptions of transparency were rooted in the deeper opportunity structures prevalent in Holyoke. Research on "implicit bias," or less overt forms of prejudice, shows that predominantly White, middle-class-led organizations tend to default to a particular set of assumptions and practices rooted in the familiar way things get done. This includes practices like topdown decision-making or avoiding the messy challenge of shifting power dynamics and norms (Packer, 2014). Several people noted in their interviews that the HFFPC needed to do more regular facilitated work together on examining racial inequities and understanding structural racialization if they wanted to begin to effectively dialogue, share stories, and be able to continue working together to build trust. As the HFFPC moved through implementation, it shifted its core steering committee membership structure, to include organizations and representatives from the city, while residents and youth joined agency partners in working groups. The steering committee thus became dominated by White, middle-class organization professionals, who were no longer challenged by a collective community voice, now lacking critical mass. One partner noted:

No one was honest about the clash of culture. If you're honest about that culture clash you can approach it with love and compassion to look at how stupid Whites can be about this stuff. [Everyone]... shared an inherent need to grasp power, fundamentally. The people who are at fault most here are the people who had the most power going in. (Interview, 2015)

The deeper question of equity is fundamental to partnerships among racially and socioeconomically diverse groups. Because these issues were not fully explored, it became a constant underlying tension between community members, staff, and agencies which often manifested in ongoing ques- 
tions of decision-making and of fund allocation.

The challenges of genuine citizen participation cannot be understated (Arnstein, 1969; Ogden, 2016; Packer, 2014). Implicit bias studies suggest that simply acknowledging that subconscious prejudices exist and that we all are guilty of them can help to diffuse their destructive influence. Packer (2014) notes that food policy councils are promising because they create the spaces where people arrive with shared values and together can challenge diverse points of view. HFFPC set out with an equitable plan that shifted the Holyoke opportunity dynamics by engaging a diverse cohort in all levels of governance. While the HFFPC participated in local gatherings to discuss racial inequity and co-sponsored a regional training on dismantling racism in later years, regular dismantling racism trainings were not structured into the HFFPC's early community action plan, and some key partner executives did not attend (Interview, 2015). One former partner argued, "We are not seeing results fast enough. It's because we were not talking about root causes" (Former partner, Interview, 2015). jon powell of the Haas Institute for a Fair and Inclusive Society notes, "In the United States... we promote the idea of race blindness... we also tend to be structurally blind. So we don't see structures.... But structures are never neutral and they affect people differently" (Insight Center for Community Economic Development, 2013, min. 2:33). While partners worked across social boundaries, the groups were not aligned in reflecting on internal organizational race dynamics and their broader implications in Holyoke (Lee \& Navarro, 2016; Packer, 2014; Sbicca, 2015). In a bravely imperfect way, the HFFPC succeeded in building moments that shifted these normative dynamics, especially in schools. But without continuous internal work on racial disparities, HFFPC alignment between partners broke down, and valued community members and nonprofit community groups stopped coming to be part of the process. Decision-making defaulted to a familiar top-down process, with little community input. The resulting impact on the organizing around school food was a lack of focus and traction.

Language usage is different for each person, due to context and life experience. This may be the key to all the challenges the HFFPC faced: that despite many hours of work together, everyone had different understandings of language (subtler than between Spanish and English translations); words like justice, race, and equity all resonated differently across the race and class spectrum of urban teens and adult project partner staff members. The HFFPC succeeded in creating new structures to bring together people from many backgrounds and perspectives to create change collaboratively, but deeper and continuous facilitated work on understanding root causes to opportunity barriers needed to occur.

The HFFPC hired a local facilitator during the planning stages, who became a mentor and trusted ally for many partners (community, youth, and agency). The facilitator acted as a translator and guide who could recognize and articulate ways to address differences and challenges over trust issues. Over the course of the grant, the HFFPC was able to engage with other technical assistance providers to help think and shape this new coalition. Perhaps because racial equity work is so complex, facilitation alone was not sufficient to build the needed trust and skills in dialogue across race and class. In hindsight, some partners noted that this might be solved by an intentional first year of skill-building to build trust and prepare partners for the foreseeable challenges building within coalition work. Another partner noted that continuous engagement with a facilitator might have also helped (Interview, 2015).

\section{Conclusion and Recommendations}

Is the food any better in the schools? Institutional barriers to serving delicious school meals remain. For instance, the new food vendor did not adopt a policy to include local produce in meals. But in a sense this was not the most pressing problem: in 2015, the Holyoke Public Schools went into state receivership for underperformance, and thus district farm-to-school discussions took a hiatus.

We conclude from our interviews and discussions that, while the quality of school food has not significantly improved, the perceptions and desires of the students, staff, and parents have changed. Stu- 
dents can articulate what they would like to see in school meals and why. The youth involved learned how to advocate for themselves through the structure of the School Food Committee. They learned about the complex global food systems (how our food gets to us from farm to fork): "I learned about Monsanto, about industrial agriculture, commodity crops..." (Youth leader, Interview, 2015); how schools procure food, and how to articulate what they need. While they did not see immediate success- "I didn't know how difficult it is to change a school system"- - they learned how to articulate what they wanted to the School Committee with their PhotoVoice project. They mention the value of "being part of social change," and of learning "the importance of community" and being in a "safe, fun environment." One explains all these things are "so important in our city where youth can fall into unsafe behavior really fast." Another former youth leader notes that families need critical knowledge in order to become effective advocates: "If students and parents aren't aware of these issues, it will take a long time to change" (Youth leaders, Interview, 2015).

A former school administrator suggests that awareness that increased among teachers and administrators over that time has influenced broader discussions about systems change in city council. He notes that teachers talk about healthy choices more often and some began to sympathize with families as they saw the root causes of struggle. He continues:

For people who have lived here all their lives, I see an awareness. People over 55. It's very easy for teachers to criticize minority kids [for] being overweight. This was new for them. Food and Fitness did that for people. Getting people to talk about food deserts. City Council candidates are putting that out as a big piece.... big idea. A School Committee person living in Ward One talked about how there's nowhere to go shopping. City official awareness is one of their [HFFPC's] biggest accomplishments. Persistence created one step before the tipping point. We are one step away with our political leaders. (Partner, Interview, 2015)
Progress in coalition-building has emerged from HFFPC's imperfect but earnest efforts. The relevant literature recommends that food policy councils start small, with quick wins balancing efforts at policy changes (Burgan \& Winne, 2012; Harper et al., 2009). After eight years, the central HFFPC disbanded, and pieces of the work were continued by the core partners: one group continued wellness efforts, and another developed new cultural crops and school food initiatives. Housed at Nuestras Raíces, which provides the backbone support, a core group of partners and school parents have designed a new project, Nuestra Comida, with funding from the W. K. Kellogg Foundation. Nuestra Comida strives to increase markets and production of cultural crops, to continue the work of leveraging school district food change "from the outside in" beginning with a charter high school, and to build pathways to jobs and higher education for youth. Together partners designed a participatory approach to youth and community leadership development, with youth and community cooking classes, student input to a new school cafeteria design, and design sharing for a high school garden at Holyoke High School. They sought technical assistance and secured a FoodCorps position to staff farm-to-school work, and began mobilizing parents. While food in the schools has not become the desired fresh, delicious, cultural meals we hear the students want, the essential systems changes have occurred to ensure that every child has the meals he or she needs and that the school community is more aware that it is possible to change the school food environment. The new program builds from the HFFPC foundation of eight years of collaborative organizing, fostering community leadership, resilience, and collective effectiveness to shift existing impeding systems and long-accepted narratives.

From these experiences, several recommendations emerge that are applicable to coalitions, food policy councils, and farm-to-school endeavors:

1. Design for engagement:

a. Gather diverse stakeholders and build capacity of new leaders; engage community leaders in all aspects of setting inclusive goals, evaluation methods, and governance structures, in order to change 
the predominant narrative.

b. Adopt and articulate anti-oppression and/or dismantling racism as central to the initiative; organize regular facilitated dismantling-racism trainings for all stakeholders and partners together, in order to build dialogue, trust, and shared understanding. Engage a highly skilled facilitator who does not have a stake in the outcome to offer facilitation and guidance to the group.

c. Design a community engagement ladder or pathway for building community leadership into all processes, with clear compensation and paid positions that reflect the value of a community member's contribution.

2. Build diverse local and regional partnerships to fuel effective systems change. HFFPC aligned multiple organizations, youth, and community members spanning health advocacy, youth advocacy, academia, urban farming, fitness and active living groups, city planners, schools, and foodservice providers.

3. Change opportunity structures: Establish clear systems and policy change targets (such as contracted agreements to source an established percentage of local produce, establishment of multistakeholder task forces, and prototypes like the salad bar).

4. Mass mobilization: Cultivate advocacy opportunities and occasions to share knowledge in regional and national policy change efforts (for example, the youth PhotoVoice project).

5. Identify a mentor or facilitator whom partners consider a coach and ally to shadow and support the leadership, build trust, help staff navigate partnerships, and build advocacy and policy strategy. Organizations hosting staff should develop a training and mentorship program to support community leaders coming into positions within the coalition so that they may be successful in their role.

6. Design participatory research and evalua- tion projects with residents (together with agency partners), identifying salient challenges, gathering data, and analyzing outcomes. Build in meeting time for residents to develop conclusions, contribute to, and review reports.

Community coalition organizing can be divisive. Even with a common agenda, mutually reinforcing activities, and a long-term, dedicated funder, communication can break down. One partner noted:

There is a human cost to people. There is no way to do this [work] without it. You do have to account for that human thing. If somehow we had acknowledged it from the outset that it's going to be the human stuff that will drive you nuts through all this, not the programs. We've seen that people have a real hard time with different agendas, money. People need training, a project buddy, and it will still hurt. (Partner, Interview, 2015)

And yet, despite real frustrations and pain, all those we interviewed share the values of improving health outcomes for Holyoke's vulnerable children and can see the long-term benefits of the work. A former staff member notes,

When I left HFFPC, I was a different person. I was wiser, I felt smarter. I really wish I had gone into that project knowing the things I knew when I had left. There were a lot of beautiful moments. Great moments. It was difficult, hard; people cried, screamed. But at the same time, there was a lot of passion and love in that group. They wanted to get a lot accomplished. A lot of good things happened. (Staff member, Interview, 2015)

The HFFPC struggled with many of the process challenges outlined in the literature about collaborative organizing, and yet there emerged lessons about community leadership and ownership, aligning partnerships, and designing racial 
equity foundation into coalitions. These findings are also significant for farm-to-school organizing, in which there is need of a common agenda across constituents, a backbone support organization, communication feedback loops, and mutually reinforcing activities (Hanleybrown, Kania, \& Kramer, 2012; Kania \& Kramer, 2011, 2013). The HFFPC sowed the seeds for Nuestra Comida, a new initiative built from these lessons learned about diverse and racially equitable engagement, and about building resilience by making the space and time to innovate collaboratively.

\section{Acknowledgements}

Many thanks to all the people who offered their heartfelt stories and analysis to build this document. Great appreciation to our early readers, Laurie La Chance and Jeff Harness, and to Linda Jo Doctor and Frank J. Omowale Satterwhite for standing by the HFFPC. We are deeply grateful to the W. K. Kellogg Foundation for funding this case study.

\section{References}

Ammons, S. (2014). Shining a light in dark places: Policy brief: Raising up the work of Southern women of color in the food system. Retrieved from http://www.centerfor socialinclusion.org/category/publications/foodsystems/

Arnstein, S. R. (1969). A ladder of citizen participation. Journal of the American Institute of Planners, 35(4), 216-224. http://dx.doi.org/10.1080/01944366908977225

Bell, J., \& Lee, M. M. (2011). Why place and race matter: Impacting health through a focus on race and place. Retrieved from http://www.policylink.org/findresources/library/why-place-and-race-matter

Bell, J., Mora, G., Hagan, E., Rubin, V., \& Karpyn, A. (2013). Access to healthy food and why it matters: A review of the research. PolicyLink and the Food Trust. Retrieved from http://www.policylink.org/findresources/library/access-to-healthy-food-and-why$\underline{\text { it-matters }}$

Burgan, M., \& Winne, M. (2012). Doing food policy councils right: A guide to development and action. Retrieved from http://www.markwinne.com/wp-content/ uploads/2012/09/FPC-manual.pdf

Coombe, C. M. (2005). Participatory evaluation: Building community while assessing change. In M.
Minkler (Ed.), Community organizing and community building for health (2nd ed., pp. 368-385). New Brunswick, New Jersey: Rutgers University Press.

Coplen, A. K., \& Cuneo, M. (2015). Dissolved: Lessons learned from the Portland Multnomah Food Policy Council. Journal of Agriculture, Food Systems, and Community Development, 5(2), 91-107. http://dx.doi.org/10.5304/jafscd.2015.052.002

Foster-Fishman, P. G., Berkowitz, S. L., Lounsbury, D. W., Jacobson, S., \& Allen, N. A. (2001). Building collaborative capacity in community coalitions: A review and integrative framework. American Journal of Community Psychology, 29(2), 241-261. http://dx.doi.org/10.1023/A:1010378613583

Giancatarino, A., \& Noor, S. (2014). Building the case for racial equity in the food system. Retrieved from http://www.centerforsocialinclusion.org/wpcontent/uploads/2014/07/Building-the-Case-forRacial-Equity-in-the-Food-System.pdf

Gottlieb, R., \& Joshi, A. (2010). Food justice. Cambridge, Massachusetts: MIT Press.

Graham, J., \& Cornwell, J. (2009). Building community economies in Massachusetts: An emerging model of economic development? In A. Amin (Ed.), The social economy: International perspectives on economic solidarity (pp. 37-65). New York: Zed Books.

Hanleybrown, F., Kania, J., \& Kramer, M. (2012). Channeling change: Making collective impact work. Stanford Social Innovation Review. Retrieved from https://ssir.org/articles/entry/channeling_change_ making collective impact work

Harper, A., Shattuck, A., Holt-Giménez, E., Alkon, A., \& Lambrick, F. (2009). Food policy councils: Lessons learned. Retrieved from the Food First/Institute for Food \& Development Policy website: https:// foodfirst.org/publication/food-policycouncils-lessons-learned/

Himmelman, A. T. (2001). On coalitions and the transformation of power relations: Collaborative betterment and collaborative empowerment. American Journal of Community Psychology, 29(2), 277284. http://dx.doi.org/10.1023/A:1010334831330

HFFPC. (2009). Cross site report to W. K. Kellogg Foundation. Holyoke, Massachusetts: Partnership in Practice.

HFFPC. (2010). Cross site report to W. K. Kellogg Foundation. Holyoke, Massachusetts: Partnership in Practice. 
HFFPC. (2011). Cross site report to W. K. Kellogg Foundation. Holyoke, Massachusetts: Partnership in Practice.

HFFPC. (2012). Cross site report to W. K. Kellogg Foundation. Holyoke, Massachusetts: Partnership in Practice.

HFFPC. (2013). Cross site report to W. K. Kellogg Foundation. Holyoke, Massachusetts: Partnership in Practice.

HFFPC. (2014). Cross site report to W. K. Kellogg Foundation. Holyoke, Massachusetts: Partnership in Practice.

Insight Center for Community Economic Development. (2013, December 16). Beyond poverty: Opportunity structures [Video file]. Retrieved from https://www.youtube.com/watch?v $=\mathrm{mf}$ Wlaejby $7 \mathrm{M}$

Kadushin, C., Lindholm, M., Ryan, D., Brodsky, A., \& Saxe, L. (2005). Why it is so difficult to form effective community coalitions. City \& Community, 4(3), 255-275. http://dx.doi.org/10.1111/j.15406040.2005.00116.x

Kang, H. (2015). “We're who we've been waiting for": Intergenerational community organizing for a healthy community. Journal of Community Practice, 23(1), 126-140. http://dx.doi.org/10.1080/10705422.2014.983214

Kania, J., \& Kramer, M. (2011). Collective impact. Stanford Social Innovation Review. Retrieved from https://ssir.org/articles/entry/collective impact

Kania, J., \& Kramer, M. (2013). Embracing emergence: How collective impact addresses complexity. Stanford Social Innovation Review. Retrieved from https://ssir.org/articles/entry/embracing emergen ce how collective impact addresses complexity

Kingdon, J. W. (2010). Agendas, alternatives, and public policies (2nd ed.). New York: Pearson.

Lee, M., \& Navarro, A. (2016, May). Equity: What it takes. Presentation at the W.K. Kellogg Foundation Capstone Conference, Decorah, Iowa.

London, J. K. (2007). Power and pitfalls of youth participation in community-based action research. Children Youth and Environments, 17(2), 406-432. Available from http://humanecology.ucdavis. edu/docs/faculty docs/crd london jonathan/ journal 8 power pitfalls youth participation.pdf
Massachusetts Department of Elementary and Secondary Education. (2015). School and district profiles: Holyoke [Data analysis]. Retrieved from http://profiles.doe.mass.edu/analysis/default.aspx? orgcode $=01370000 \&$ orgtypecode $=5 \&$

National Farm to School Network. (2016). About farm to school: What is farm to school? Retrieved February 1, 2016, from http://www.farmtoschool. org/about/what-is-farm-to-school

Ogden, C. (2016, January 20). Network development as a leverage for systems change. Retrieved from http://interactioninstitute.org/networkdevelopment-as-leverage-for-system-change/

Packer, M. M. (2014). Civil subversion: Making "quiet revolution" with the Rhode Island Food Policy Council. Journal of Critical Thought and Praxis, 3(1). http://lib.dr.iastate.edu/jctp/

Reece, J., Gambhir, S., powell, j., \& Grant-Thomas, A. (2009). The geography of opportunity: Building communities of opportunity in Massachusetts. Retrieved from http://kirwaninstitute.osu.edu/my-product/thegeography-of-opportunity-building-communitiesof-opportunity-in-massachusetts/

Sands, C. H., Bankert, S. C., Rataj, S., Maitin, M., \& Sostre, J. (2014). "Call for partnerships": An innovative strategy to establish grassroots partnerships to transform the food and fitness environments. Community Development, 45(3), 263-278. http://dx.doi.org/10.1080/15575330.2014.902856

Sbicca, J. (2015). Solidarity and sweat equity: For reciprocal food justice research. Journal of Agriculture, Food Systems, and Community Development, 5(4), 63-67. http://dx.doi.org/10.5304/jafscd.2015.054.004

Scherb, A., Palmer, A., Frattaroli, S., \& Pollack, K. (2012). Exploring food system policy: A survey of food policy councils in the United States. Journal of Agriculture, Food Systems, and Community Development, 2(4), 3-14. http://dx.doi.org/10.5304/jafscd.2012.024.007

U.S. Census Bureau. (2016). United States Census Bureau QuickFacts [Dataset]. Retrieved from http://quickfacts.census.gov/qfd/states/25/25308 40.html

Wallerstein, N. (1992). Powerlessness, empowerment, and health: Implications for health promotion programs. American Journal of Health Promotion, 6(3), 197-205. http://ahp.sagepub.com/ 
Weaver-Hightower, M. B. (2011). Why education researchers should take school food seriously. Educational Researcher, 40(1), 15-21. http://dx.doi.org/10.3102/0013189X10397043

Wolff, T. (2016). Ten places where collective impact gets it wrong. Global Journal of Community Psychology Practice, 7(1). Retrieved from http://www.gjcpp. org $/$ en $/$ resource.php? issue $=21 \&$ resource $=200$
Zukoski, A., \& Luluquisen, M. (2002). Participatory evaluation: What is it? Why do it? What are the challenges? Community-Based Public Health Policy and Practice, 5, 1-6. Retrieved from https://depts. washington.edu/ccph/pdf files/Evaluation.pdf 


\section{Appendix. Interview Questions}

1. When did you become involved in the HFFPC?

2. What do you believe was the chief task(s) of the HFFPC?

3. What was your role?

4. What did you expect from the project for your personal development?

5. Were your needs met? Why/Why not?

6. Name some of the HFFPC's accomplishments that impressed you the most.

7. Discuss some of the key shortfalls.

8. What might another community learn from HFFPC's experience?

9. In thinking about HFFPC's collaborative work to improve school food and increase children's knowledge of healthy eating, to what extent was the collaborative work successful? What changes did you see?

10. What challenges did HFFPC encounter in supporting Holyoke Public Schools to serve more fresh food to children?

11. Has the work with HFFPC changed you (if any)?

12. Any other thoughts that you would like to add? 